\title{
Temperature adaptation in Lactobacillus fermentum: interconversions of oleic, vaccenic and dihydrosterulic acids
}

\author{
M. SUUTARI* and S. LAAKSo \\ Helsinki University of Technology, Department of Chemical Engineering, Laboratory of Biochemistry and Microbiology, \\ SF-02150 Espoo, Finland.
}

(Received 22 August 1991; revised 11 November 1991; accepted 25 November 1991)

\begin{abstract}
The interchange of octadecenoic acids and dihydrosterulic acid was a response of aerobically growing Lactobacillus fermentum to changes in growth temperature. Oleic and vaccenic acid contents decreased both at temperatures below $20^{\circ} \mathrm{C}$ and above $26^{\circ} \mathrm{C}$, showing mirror image behaviour, with a concomitant increase in dihydrosterulic acid. A temperature-dependent shift from vaccenic to oleic acid synthesis, and the conversion of the latter to dihydrosterulic acid was responsible for the overall change. Consequently, the degree of fatty acid unsaturation decreased at temperatures above $26^{\circ} \mathrm{C}$, whereas the degree of cyclization increased. The converse occurred below $20^{\circ} \mathrm{C}$. The relative amount of lactobacillic acid, total cellular fatty acid content, and mean fatty acid chain length were practically temperature-independent. The occurrence of oleic acid is thought to be related to aerobic growth conditions.
\end{abstract}

\section{Introduction}

The membrane and mesosomal lipids of typical lactobacilli contain even-carbon, straight-chain saturated and monoenoic acids, together with cyclopropane acids (Thorne \& Kodicek, 1962; Croom et al., 1964; Veerkamp, 1971). Their relative amounts vary according to culture conditions such as growth phase and rate, medium composition, and temperature (Croom et al., 1964; Henderson \& McNeill, 1966; Veerkamp, 1971; Uchida \& Mogi, 1973b; Smittle et al., 1974; Uchida, 1975; Gill \& Suisted, 1978). As a consequence, the physical properties of structural lipids vary, and influence many fundamental cellular functions, including membrane transport and the activity of membranebound enzymes involved with energy metabolism (Cronan \& Gelmann, 1975; Sandermann, 1978; Brenner, 1984; Neidleman, 1987). An understanding of such lipidassociated phenomena is vital in maintaining cellular viability during the processing and preservation of many fermented products, e.g. low temperature storage (Mazur, 1970; Smittle et al., 1972, 1974; Calcott, 1986).

The long-chain fatty acids of lactobacilli are formed in a similar way to those of Escherichia coli. The enzymes involved are acetyl-CoA carboxylase (ACC), which produces malonyl-CoA, and a complex of at least eight

- Author for correspondence. Tel. (0) 45125 51; fax (0) 462373. different functional protein units called fatty acid synthetase (FAS II) (O'Leary, 1965; Birnbaum, 1969, 1970; Weeks \& Wakil, 1970). The double bond of monounsaturated vaccenic, palmitoleic and shorter chain $\omega-7$ acids is formed anaerobically during elongation by the enzyme $\beta$-hydroxyacyl- $\beta, \gamma$-dehydratase (Scheuerbrandt \& Bloch, 1962; Norris et al., 1964; O'Leary, 1965).

Oleic, and other monoenoic acids of the $\omega-9$ series are rarely detected in lactobacilli (Nakano et al., 1979; Uchida \& Mogi, 1972, 1973a). However, in Lactobacillus plantarum oleic acid or its derivative regulates fatty acid synthesis by repressing the formation and activity of ACC and FAS II (Henderson \& McNeill, 1966; Birnbaum, 1970; Weeks \& Wakil, 1970). This does not occur in $E$. coli which contains only vaccenic acid (Silbert \& Vagelos, 1967; Silbert et al., 1968). In microbes, oleic acid can be formed by two routes, either anaerobically as presented above for $\omega-7$ acids or by oxygen-dependent desaturases (Scheuerbrandt \& Bloch, 1962). Monoenoic fatty acids can further be cyclized to cyclopropane acids by the enzyme cyclopropane synthetase, which adds a methylene carbon bridge from $S$-adenosyl-L-methionine (SAM) across the double bond. Thus, lactobacillic acid is formed from vaccenic acid (Chalk \& Kodicek, 1961; Liu \& Hofmann, 1962; Law, 1971; Goldfine, 1972; Cronan et al., 1979) and, interestingly, when oleic acid is added to the growth medium of $L$. plantarum, it is cyclized to 
dihydrosterulic acid (Henderson \& McNeill, 1966; Polachek et al., 1966; Buist \& McLean, 1981).

In this paper, we report the occurrence of oleic acid as a natural constituent of aerobically grown, heterofermentative Lactobacillus fermentum, and demonstrate its role in temperature adaptation via interconversions with vaccenic and dihydrosterulic acid.

\section{Methods}

Strain and growth conditions. The bacterium used was Lactobacillus fermentum ATCC 14931. The strain was stored in $10 \%(\mathrm{v} / \mathrm{v})$ glycerol (Merck) at $-60^{\circ} \mathrm{C}$, and grown in $250 \mathrm{ml}$ Erlenmeyer flasks containing $50 \mathrm{ml}$ MRS-broth (Difco). The flasks were shaken at 240 r.p.m. in a Gallenkamp orbital shaker/incubator (Model INR 200 010V), and growth was monitored with a Klett-Summerson colorimeter (filter no. 66). For preparation of inocula, cells were grown to late exponential growth phase (150-200 Klett units); $1 \mathrm{ml}$ of this culture was transferred into a shake flask containing the same medium and allowed to grow to the exponential phase $(70-80 \mathrm{Klett}$ units). This culture $(1 \mathrm{ml})$ was inoculated into four parallel flasks to be used for analyses. All the stages were carried out at $15,20,26,30,35$ and $40^{\circ} \mathrm{C}$. The fatty acid composition was determined in the early-exponential ( 50 Klett units), exponential (100 Klett units), late-exponential (150 Klett units) and stationary ( $>200 \mathrm{Klett}$ units) phases. The total fatty acid content of cells was determined in the exponential phase.

To determine the growth temperature maximum, the microbe was grown on agar in a cuvette of a plate-type temperature gradient incubator (Gradiplate). The medium used was MRS-broth solidified with $2 \%(w / v)$ agar.

Analyses. To determine the fatty acid composition, samples $(5 \mathrm{ml})$ of culture suspensions were centrifuged for $10 \mathrm{~min}(5000 \mathrm{~g})$. The supernatant was removed and the cells were resuspended in $5 \mathrm{ml}$ of tap water. Centrifugation was repeated, the water was removed, and cells were frozen under an $\mathrm{N}_{2}$ stream and stored $\left(-20^{\circ} \mathrm{C}\right)$ for 1-10 days. To determine the cellular fatty acid content, the remaining bacterial culture suspension was harvested and washed as described above. The bacterial cells were lyophilized and weighed, an internal standard (heptadecanoic acid methyl ester, Sigma) was added, and the fatty acid composition was determined as follows.

Bacterial fatty acid esters were saponified, and extracted as methylesters, as described by Suutari et al. (1990). The major fatty acids were identified from their GLC peak retention times relative to fatty acid methyl ester standards (Supelco) and by GLC-MS. GLC was done using a Hewlett-Packard model 5890A gas chromatograph equipped with a flame ionization detector, a capillary inlet system and a model 7673A high-speed automatic liquid sampler with a $10 \mu$ l syringe. The conditions were as follows: HP-FFAP $(25 \mathrm{~m} \times 0.2 \mathrm{~mm} \times 0.3 \mu \mathrm{m})$ column; carrier gas helium, column flow-rate approx. $1.0 \mathrm{ml} \mathrm{min}^{-1}$; total hydrogen flow-rate to the detector $40 \mathrm{ml} \mathrm{min}^{-1}$; make-up gas, helium, flow-rate $30 \mathrm{ml} \mathrm{min}^{-1}$; septum purge flow-rate $1-2 \mathrm{ml} \mathrm{min}^{-1}$; split ratio $1: 20$; column inlet pressure, $150 \mathrm{kPa}$; injector temperature, $250{ }^{\circ} \mathrm{C}$; detector temperature, $250^{\circ} \mathrm{C}$; oven temperature, programmed from $70^{\circ} \mathrm{C}$ to $200^{\circ} \mathrm{C}$ at the rate of $25^{\circ} \mathrm{C} \mathrm{min}{ }^{-1}$. Peak areas were measured using a Hewlett-Packard model 3396A integrator. Combined GLC-MS of the fatty acid methyl esters was carried out using the GLC chromatograph described above, and equipped with a HewlettPackard mass selective detector 5971A. GLC conditions were as presented above, exept that column inlet pressure was $70 \mathrm{kPa}$. The mass spectra were recorded at an electron energy of $70 \mathrm{eV}$ and a trap current of $300 \mu \mathrm{A}$. The ion source temperature was $180^{\circ} \mathrm{C}$, and the molecular separator temperature $135^{\circ} \mathrm{C}$.
Calculations: The growth rate was determined from the slope of the growth curve in the exponential growth phase. The relative fatty acid composition was estimated as a percentage of the total peak area, and expressed as a mean value from exponential and late exponential growth phases. The total fatty acid content of the cells was defined as the proportion of cell dry weight $(w / w)$ consisting of fatty acid methyl esters. The degree of fatty acid unsaturation $\left(\Delta \mathrm{mol}^{-1}\right)$ in the lipid fraction was calculated as $[\Sigma(\%$ monoene $)] / 100$, and the degree of cyclization $\left(\Delta \mathrm{mol}^{-1}\right)$ as $[\Sigma(\%$ cyclic fatty acid $)] / 100$. The mean chain length of the fatty acids was expressed as the mean number of carbon atoms in the fatty acid chain. The standard deviation $(n=8)$ was $<0.9 \%$.

\section{Results and Discussion}

\section{Effect of temperature on fatty acid composition}

The temperatures used $\left(15-40^{\circ} \mathrm{C}\right)$ covered most of the growth range of $L$. fermentum. Growth was extremely slow at $15^{\circ} \mathrm{C}$ (Fig. 1), and there was no growth at $10^{\circ} \mathrm{C}$. According to Buchanan \& Gibbons (1974), L. fermentum does not grow even at $15^{\circ} \mathrm{C}$. Thus, the growth temperature minimum of our organism may be estimated to be near $15^{\circ} \mathrm{C}$. The highest temperature $\left(40^{\circ} \mathrm{C}\right)$ in the shake flask cultivations was $6-7^{\circ} \mathrm{C}$ below the growth temperature maximum $\left(46-47^{\circ} \mathrm{C}\right)$, as determined by the temperature gradient technique. This agrees well with the earlier observation that $L$. fermentum grows at $45^{\circ} \mathrm{C}$ (Buchanan \& Gibbons 1974).

Within the temperature range used, seven fatty acids, accounting for over $95 \%$ of total fatty acid in all growth phases were found (Fig. 2). They were identified as myristic, palmitic, palmitoleic, oleic, cis-vaccenic, dihydrosterulic (cis-9,10-methyloctadecanoate) and lactobacillic (cis-11,12-methyloctadecanoate) acids. Temperature markedly affected their relative amounts. However, the cellular fatty acid content in the exponential growth phase was low $(1.5-2.5 \%)$, and showed no significant temperature dependence. Therefore, the temperatureinduced changes in the proportions of fatty acids did not greatly reflect changes in the overall efficiency of fatty acid synthesis.

The major temperature response in fatty acid composition was limited to the interchange of the octadecenoic acids and dihydrosterulic acid (Fig. 2). Oleic and vaccenic acid decreased when temperatures were either reduced below $20^{\circ} \mathrm{C}$ or increased above $26^{\circ} \mathrm{C}$. Their fatty acid contents also showed mirror image behaviour, with a concomitant increase in dihydrosterulic acid. In addition, the proportion of myristic acid increased slightly at the temperature extremes.

\section{Oleic acid and its cyclization in temperature adaptation}

The shifts from vaccenic acid to oleic acid, and further to dihydrosterulic acid, occurred at both the lowest and 


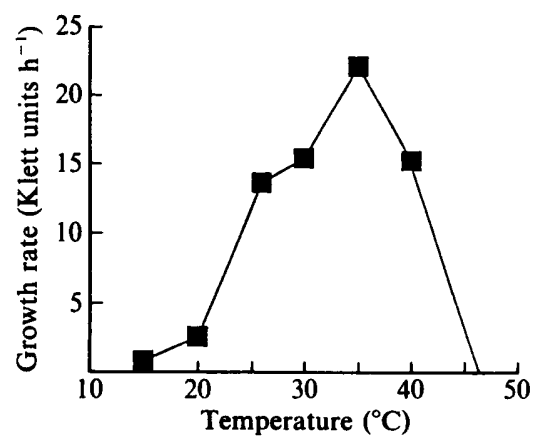

Fig. 1. Dependence of growth rate of $L$. fermentum on temperature.

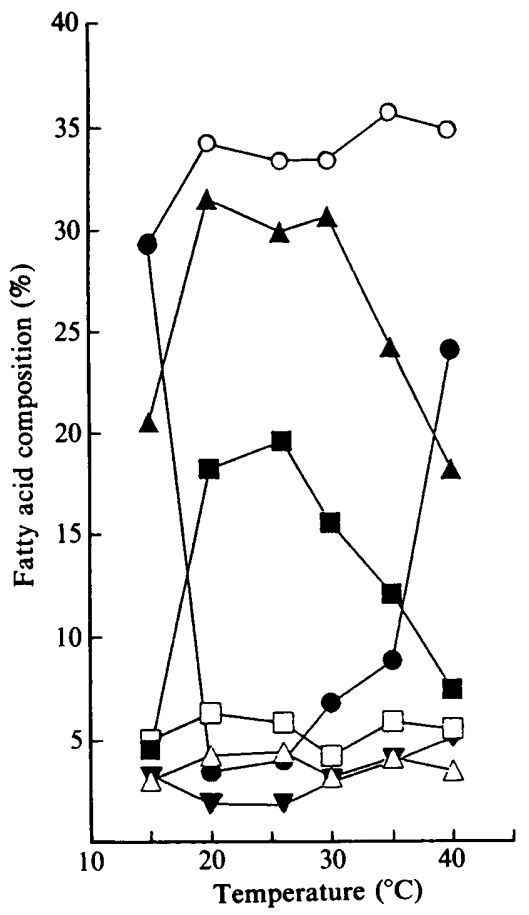

Fig. 2. Effect of temperature on fatty acid profiles of exponential cultures of $L$. fermentum. Symbols: $\bullet$, dihydrosterulic acid; $O$, palmitic acid; $\Delta$, oleic acid; $\Delta$, lactobacillic acid; $\boldsymbol{\square}$, vaccenic acid; $\square$, palmitoleic acid; $\boldsymbol{\nabla}$, myristic acid.

highest temperatures (Fig. 2). Oleic acid might be formed either aerobically by the desaturase from stearic acid or its derivative, or anaerobically during fatty acid elongation by the enzyme $\beta$-hydroxyacyl- $\beta, \gamma$-dehydratase (Scheuerbrandt \& Bloch, 1962; Norris et al., 1964). The importance of oxygen in oleic acid formation supports the presence of a desaturase such as those found in yeasts and certain bacteria. Neither we nor Rizzo et al. (1987) detected significant amounts of oleic acid in anaerobically grown $L$. fermentum. The $\beta$-hydroxyacyl- $\beta, \gamma$-dehydratase of our organism might shift between vaccenic and the stearic acid formation depending on tempera- ture, and stearic acid would then be further desaturated to oleic acid. However, an anaerobic route for the synthesis of $\omega-7$ and $\omega-9$ olefinic fatty acids cannot be ruled out. This has been proposed earlier e.g. for Clostridium butyricum (Goldfine \& Bloch, 1961), and for the genus Pediococcus which has a fatty acid pattern similar to that of lactobacilli (Uchida \& Mogi, 1972). In the latter case, the specificity of the $\beta$-hydroxy-acyl- $\beta, \gamma-$ dehydratase to the chain length of the substrate might be temperature-dependent.

The proportion of the other cyclic fatty acid, lactobacillic acid, was low (3.5-4.5\%) and practically temperature independent even in the presence of high amounts of vaccenic acid. The membrane bound cyclopropane synthetase has been reported to have a strong preference for $\omega-7$ monoenes (Goldfine \& Panos, 1971; Goldfine, 1972; Cox et al., 1973), which are acylated in phospholipids in a correct micellar state (Zalkin et al., 1963; Chung \& Law, 1964; Thomas \& Law, 1966; Law, 1971). However, the present data on $L$. fermentum favours a preference for $\omega-9$ monoenic substrates especially at extreme growth temperatures. Alternatively, multiple cyclopropane synthetases may exist in lactobacilli. Inducible and constitutive enzymes have been detected in Pseudomonas denitrificans and E. coli, respectively (Jaques, 1981; Cronan, 1968). The enzymes synthesizing oleic, cis-vaccenic and dihydrosterulic acids are clearly under some form of coordinate control.

Effect of temperature on fatty acid unsaturation and cyclization, and the mean chain length

The degree of fatty acid unsaturation decreased with increasing temperature above $26^{\circ} \mathrm{C}$, while the degree of cyclization increased (Fig. 3a). The proportion of unsaturated fatty acids is often reduced with increasing growth temperature to maintain ideal membrane fluidity (Farrell \& Rose, 1967; Fulco, 1974; Cronan \& Gelmann, 1975; Neidleman, 1987; Suutari et al., 1990). However, the formation of cyclopropane acids from unsaturated fatty acids does not necessarily alter the physicochemical properties of lipids (Cullen et al., 1971; Van Deenen, 1971; Cronan et al., 1979). Nevertheless, cyclopropane fatty acids are thought to make membranes more stable during exposure to adverse environmental conditions (Cronan, 1968; Dufourc et al., 1984). In any case, the strong shift between the degree of fatty acid unsaturation and cyclization in response to temperature changes indicates its physiological significance to $L$. fermentum. Interestingly, opposite behaviour occurred in these proportions at temperatures below $20^{\circ} \mathrm{C}$, near the growth minimum, and concomitantly the growth rate fell markedly. 

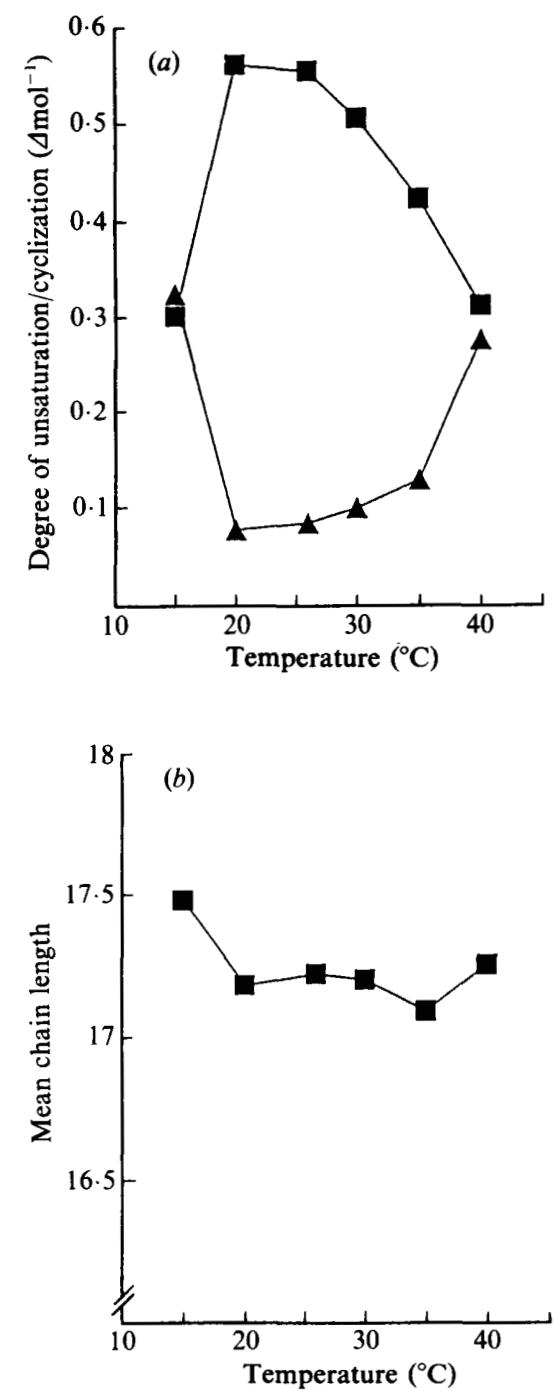

Fig. 3. Effect of temperature on (a) the degree of fatty acid unsaturation $(\boldsymbol{D})$ and cyclization $(\boldsymbol{A}),(b)$ the mean chain length, both in exponential cultures.

The mean fatty acid chain length (Fig. $3 b$ ) was practically temperature-independent. The increments near both extreme temperatures can be explained by the increasing proportion of dihydrosterulic acid at the expense of octadecenoic acids. Thus, the steps in fatty acid biosynthesis determining the mean chain length of fatty acids are not effected by temperature in L. fermentum.

The roles of cyclic fatty acids and oxygen in temperature adaptation

This study demonstrates that the interplay of oleic, vaccenic and dihydrosterulic acids is a physiologically significant response of lactobacilli to changing growth

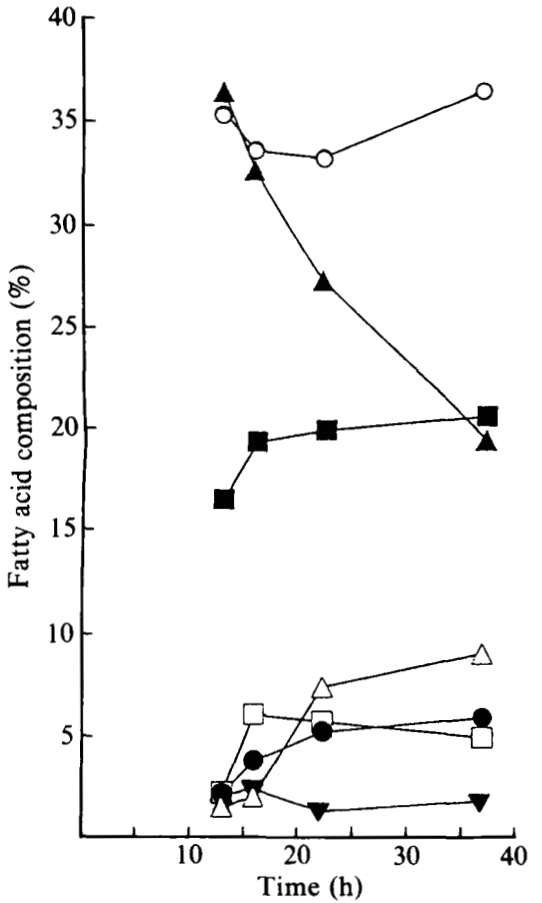

Fig. 4. Effect of culture age on the fatty acid composition of L. fermentum. Symbols as Fig. 2.

temperature. Although the existence of lactobacillic and other cyclic fatty acids is long established (Hofmann $e t$ al., 1952; Hofmann \& Sax, 1953), their role is still poorly understood (Cronan et al., 1979; Dufourc et al., 1984; Schweizer, 1989). Their appearance is often connected with disadvantageous growth conditions such as extreme temperatures, entering stationary growth phase and decreasing pH (Knivett \& Cullen, 1965; Cronan, 1968; Law, 1971; Veerkamp, 1971; Uchida \& Mogi, 1973b; Cronan et al., 1974; Uchida, 1975; Gill \& Suisted, 1978). Similarly, the data presented showed that dihydrosterulic acid was formed in L. fermentum at extreme temperatures (Fig. 2) concomitantly with decreasing growth rates (Fig. 1). Furthermore, the proportions of dihydrosterulic and lactobacillic acid increased at the expense of oleic acid (Fig. 4) upon ageing of the cells. This suggests that cyclic fatty acids might protect lactobacilli from adverse environmental effects. Indeed lactobacillic acid has been shown to stabilize lactobacilli in liquid nitrogen (Smittle et al., 1974). Nor can it be ruled out that cyclopropane acids protect lactobacilli against other microbes and viruses. When $E$. coli is infected with phage $\mathrm{T} 3$ the formation of cyclic fatty acids is inhibited by a phage-encoded SAM cleavage enzyme (O'Leary, 1965; Cronan et al., 1979). Being energetically expensive to synthesize (Taylor \& Cronan, 1976), cyclic acids might also serve as energy stores under starvation conditions created by factors other than those related to energy or lipid metabolism. 
The occurrence of oleic acid and, accordingly, dihydrosterulic acid was clearly dependent on oxygen. Therefore, despite the fact that $L$. fermentum maintains a fermentative metabolism under aerobic conditions (Buchanan \& Gibbons, 1974; Condon, 1987), oxygen has an important effect on metabolism related to membrane structure and function. No cyclic fatty acids were detected in obligately anaerobic rumen lactobacilli (Miyagawa, 1982). The induction of oleic acid synthesis might be related to the protection of the cells against the deleterious effects of oxygen.

We thank Mrs U. Âmman for her technical assistance. The financial support of the Technology Development Centre (TEKES) is gratefully acknowledged.

\section{References}

Birnbaum, J. (1969). Coenzyme repression of acetyl-CoA carboxylase by (+)-biotin. Archives of Biochemistry and Biophysics 132, 436-441.

BIRNBaUM, J. (1970). Repression of acetyl-coenzyme A carboxylase by unsaturated fatty acids: relationship to coenzyme repression. Journal of Bacteriology 104, 171-176.

BRENNER, R. R. (1984). Effect of unsaturated acids on membrane structure and enzyme kinetics. Progress in Lipid Research 23, 69-96.

BuchanAN, R. E. \& GibBons, N. E. (editors) (1974). Bergey's Manual of Determinative Bacteriology, 8th edn, pp. 576-593. Baltimore: Williams \& Wilkins.

Buist, P. H. \& McLean, D. B. (1981). The biosynthesis of cyclopropane fatty acids. I. Feeding experiments with oleic acid9,10- $d_{2}$, oleic acid-8,8,11,11- $d_{4}$, and L-methionine-methyl- $d_{3}$. Canadian Journal of Chemistry 59, 828-838.

CalcotT, P. H. (1986). Cryopreservation of micro-organisms. CRC Critical Reviews in Biotechnology 4, 279-297.

ChalK, K. J. I. \& KodiceK, E. (1961). The incorporation of [Me${ }^{14} \mathrm{C}$ ]methionine into lactobacillic acid. Biochimica et Biophysica Acta 50, 579-581.

Chung, A. E. \& LAW, J. H. (1964). Biosynthesis of cyclopropane compounds. VI. Product inhibition of cyclopropane fatty acid synthetase by $S$-adenosylhomocysteine and reversal of inhibition by a hydrolytic enzyme. Biochemistry 3, 1989-1993.

ConDON, S. (1987). Responses of lactic acid bacteria to oxygen. FEMS Microbiology Reviews 46, 269-280.

Cox, G. S., Thomas, E., Kabacx, H. R. \& Weissbach, H. (1973). Synthesis of cyclopropane fatty acids in isolated bacterial membranes. Archives of Biochemistry and Biophysics 158, 667-676.

CRONAN, J. E., JR (1968). Phospholipid alterations during growth of Escherichia coli. Journal of Bacteriology 95, 2054-2061.

Cronan, J. E., JR \& Gelmann, E. P. (1975). Physical properties of membrane lipids: biological relevance and regulation. Bacteriological Reviews 39, 232-256.

Cronan, J. E., JR, NunN, W. D. \& Batchelor, J. G. (1974). Studies on the biosynthesis of cyclopropane fatty acids in Escherichia coli. Biochimica et Biophysica Acta 348, 63-75.

Cronan, J. E., JR, Reed, R., Taylor, F. R. \& Jackson, M. B. (1979). Properties and biosynthesis of cyclopropane fatty acids in Escherichia coli. Journal of Bacteriology 138, 118-121.

Croom, J. A., McNeill, J. J. \& Tove, S. B. (1964). Biotin deficiency and the fatty acids of certain biotin-requiring bacteria. Journal of Bacteriology 88, 389-394.

Cullen, J., Phillips, M. C. \& Shipley, G. G. (1971). The effects of temperature on the composition and physical properties of the lipids of Pseudomonas fluorescens. Biochemical Journal 125, 733-742.

DufourC, E. J., Smith, I. C. P. \& JARReLl, H. C. (1984). Role of cyclopropane moieties in the lipid properties of biological membranes: A ${ }^{2}$ H NMR structural and dynamical approach. Biochemistry 23, $2300-2309$.
FARRELL, J. \& Rose, A. (1967). Temperature effects on microorganisms. Annual Review of Microbiology 21, 101-120.

Funco, A. J. (1974). Metabolic alterations of fatty acids. Annual Review of Biochemistry 43, 215-241.

GILL, C. O. \& SuISTED, J. R. (1978). The effects of temperature and growth rate on the proportion of unsaturated fatty acids in bacterial lipids. Journal of General Microbiology 104, 31-36.

GoldFINE, H. (1972). Comparative aspects of bacterial lipids. Advances in Microbiol Physiology 8, 1-58.

GoldFINE, H. \& BLOCH, K. (1961). On the origin of unsaturated fatty acids in Clostridia. Journal of Biological Chemistry 236, 2596-2601.

Goldfine, H. \& Panos, C. (1971). Phospholipids of Clostridium butyricum. IV. Analysis of the positional isomers of monounsaturated and cyclopropane fatty acids and alk-1'-enyl ethers by capillary column chromatography. Journal of Lipid Research 12, 214-220.

Henderson, T. O. \& MCNeILl, J. J. (1966). The control of fatty acid synthesis in Lactobacillus plantarum. Biochemical and Biophysical Communications 25, 662-669.

HofmanN, K. \& SaX, S. M. (1953). The chemical nature of the fatty acids of Lactobacillus casei. Journal of Biological Chemistry 205, 5563.

Hofmann, K., Lucas, R. A. \& SaX, S. M. (1952). The chemical nature of the fatty acids of Lactobacillus arabinosus. Journal of Biochemistry 195, 473-485.

JAQUES, N. A. (1981). Studies on cyclopropane fatty acid synthesis. Correlation between the state of reduction of respiratory components and the accumulation of methylene hexadecanoic acid by Pseudomonas denitrificans. Biochimica et Biophysica Acta 665, 270-282.

KNIVETT, V. A. \& Cullen, J. (1965). Some factors affecting cyclopropane acid formation in Escherichia coli. Biochemical Journal 96, 771-776.

LAW, J. H. (1971). Biosynthesis of cyclopropane rings. Accounts of Chemical Research 4, 199-203.

LiU, T. Y. \& HofmanN, K. (1962). Cyclopropane ring biosynthesis. Biochemistry 1, 189-191.

MAZUR, P. (1970). Cryobiology: the freezing of biological systems. The responses of living cells to ice formation are of theoretical interest and practical concern. Science 168, 939-949.

MiYagaWA, E. (1982). Cellular fatty acid and fatty aldehyde composition of rumen bacteria. Journal of General and Applied Microbiology 28, 389-408.

NaKano, M., OHE, H. \& Fujino, Y. (1979). Glyceroglycolipids in Lactobacillus sake. Obihiro Chikusan Daigaku Gakujutsu Kenkyu Hokoku, Dai-1-Bu 11, 511-518 (also Chemical Abstracts 92 106997v).

NeIDLEMAN, S. L. (1987). Effect of temperature on lipid unsaturation. Biotechnology and Genetic Engineering Reviews 5, 245-268.

Norris, A. T., Matsumura, S. \& Bloch, K. (1964). Fatty acid synthetase and $\beta$-hydroxydecanoyl coenzyme $A$ dehydrase from Escherichia coli. Journal of Biological Chemistry 239, 3653-3662.

O'Leary, W. M. (1965). Decenoic, dodecenoic, and tetradecenoic acids in the Lactobacteriaceae. Biochemistry 4, 1621-1627.

Polacheck, J. W., Tropp, B. E. \& LAW, J. H. (1966). Biosynthesis of cyclopropane compounds. Journal of Biological Chemistry 241, 33623364.

Rizzo, A. F., Korkeala, H. \& Mononen, I. (1987). Gas chromatography analysis of cellular fatty acids and neutral monosaccharides in the identification of lactobacilli. Applied and Environmental Microbiology 53, 2883-2888.

SANDERMANN, H., JR (1978). Regulation of membrane enzymes by lipids. Biochimica et Biophysica Acta 515, 209-237.

SCHEUERBRANDT, G. \& BLOCH, K. (1962). Unsaturated fatty acids in microorganisms. Journal of Biological Chemistry 237, 2064-2068.

SCHWEIZER, E. (1989). Biosynthesis of fatty acids and related compounds. In Microbial Lipids, pp. 3-50. Edited by C. Ratledge \& S. G. Wilkinson. London: Academic Press.

Silbert, D. F. \& VAGelos, P. R. (1967). Fatty acid mutant of E. coli lacking a $\beta$-hydroxydecanoyl thioester dehydrase. Proceedings of the National Academy of Sciences of the United States of America 58, 1579-1586.

Silbert, D. F., RuCh, F. \& Vagelos, P. R. (1968). Fatty acid replacements in a fatty acid auxotroph of Escherichia coli. Journal of Bacteriology 95, 1658-1665. 
Smittle, R. B., Gilliland, S. E. ANd SpeCK, M. L. (1972). Death of Lactobacillus bulgaricus resulting from liquid nitrogen freezing. Applied Microbiology 24, 551-554.

Smittle, R. B., Gilliland, S. E., SPeck, M. L. \& Walter, W. M., JR (1974). Relationship of cellular fatty acid composition to survival of Lactobacillus bulgaricus in liquid nitrogen. Applied Microbiology 27, 738-743.

SuUtari, M., LiUkKonen, K. \& LaAkso, S. (1990). Temperature adaptation in yeasts: the role of fatty acids. Journal of General Microbiology 136, 1469-1474.

TAYLOR, F. \& CrONAN, J. E., JR (1976). Selection and properties of Escherichia coli mutants defective in the synthesis of cyclopropane fatty acids. Journal of Bacteriology 125, 518-523.

Thomas, P. J. \& LAW, J. H. (1966). Biosynthesis of cyclopropane compounds. IX. Structural and stereochemical requirements for the cyclopropane synthetase substrate. Journal of Biological Chemistry 241, 5013-5018.

THORNE, K. J. I. \& KoDICEK, E. (1962). The metabolism of acetate and mevalonic acid by lactobacilli. IV. Analysis of the fatty acids by gasliquid chromatography. Biochimica et Biophysica Acta 59, 306-312.

UCHIDA, K. (1975). Effects of cultural conditions on the cellular fatty acid composition of Lactobacillus heterohiochii, an alcoholophilic bacterium. Agricultural and Biological Chemistry 39, 837-842.
UCHIDA, K. \& MogI, K. (1972). Cellular fatty acid spectra of Pediococcus species in relation to their taxonomy. Journal of General and Applied Microbiology 18, 109-129.

UCHIDA, K. \& MOGI, K. (1973a). Cellular fatty acid spectra of Sporolactobacillus and some other Bacillus-Lactobacillus intermediates as a guide to their taxonomy. Journal of General and Applied Microbiology 19, 129-140.

UCHIDA, K. \& MoGI, K. (1973b). Cellular fatty acid spectra of hiochi bacteria, alcohol-tolerant lactobacilli, and their group separation. Journal of General and Applied Microbiology 19, 233-249.

VAN DEENEN, L. L. M. (1971). Chemistry of phospholipids in relation to biological membranes. Pure and Applied Chemistry 25, 25-56.

VEERKAMP, J. H. (1971). Fatty acid composition of Bifidobacterium and Lactobacillus strains. Journal of Bacteriology 108, 861-867.

WEEKS, G. \& WAKIL, S. J. (1970). Studies on the control of fatty acid metabolism. II. The inhibition of fatty acid synthesis in Lactobacillus plantarum by exogenous fatty acid. Journal of Biological Chemistry 245, 1913-1921.

ZALKIN, H., LAW, J. H. \& GoldFINE, H. (1963). Enzymatic synthesis of cyclopropane fatty acids catalyzed by bacterial extracts. Journal of Biological Chemistry 238, 1242-1248. 